\title{
Evaluation of Single Field Uniform Dose (SFUD) Proton Pencil Beam Scanning (PBS) Planning Strategy for Lung Mobile Tumor Using a Digital Phantom
}

\author{
Gang Liu ${ }^{1,2}$, Hong Quan ${ }^{1 *}$, Xiaoqiang Li², Craig Stevens ${ }^{2}$, Di Yan², Xuanfeng Ding# \\ ${ }^{1}$ School of Physics and Technology, Wuhan University, Wuhan, China \\ ${ }^{2}$ Department of Radiation Oncology, Beaumont Health System, Royal Oak, MI, USA \\ Email: "Xuanfeng.ding@beaumont.org
}

How to cite this paper: Liu, G., Quan, H., Li, X.Q., Stevens, C., Yan, D. and Ding, X.F. (2016) Evaluation of Single Field Uniform Dose (SFUD) Proton Pencil Beam Scanning (PBS) Planning Strategy for Lung Mobile Tumor Using a Digital Phantom. International Journal of Medical Physics, Clinical Engineering and Radiation Oncology, 5, 213 229.

http://dx.doi.org/10.4236/ijmpcero.2016.54023

Received: August 17, 2016

Accepted: September 27, 2016

Published: September 30, 2016

Copyright $\odot 2016$ by authors and Scientific Research Publishing Inc. This work is licensed under the Creative Commons Attribution International License (CC BY 4.0).

http://creativecommons.org/licenses/by/4.0/

\section{Open Access}

\begin{abstract}
Purpose: To quantitatively evaluate four different Proton SFUD PBS initial planning strategies for lung mobile tumor. Methods and Materials: A virtual lung patient's four-dimensional computed tomography (4DCT) was generated in this study. To avoid the uncertainties from target delineation and imaging artifacts, a sphere with diameter of $3 \mathrm{~cm}$ representing a rigid mobile target (GTV) was inserted into the right side of the lung. The target motion is set in superior-inferior (SI) direction from -5 $\mathrm{mm}$ to $5 \mathrm{~mm}$. Four SFUD planning strategies were used based on: 1) Maximum-Intensity-Projection Image (MIP-CT); 2) CT_average with ITV overridden to muscle density (CTavg_muscle); 3) CT_average with ITV overridden to tumor density (CTavg_tumor); 4) CT_average without any override density (CTavg_only). Dose distributions were recalculated on each individual phase and accumulated together to assess the "actual" treatment. To estimate the impact of proton range uncertainties, $+/-3.5 \%$ CT calibration curve was applied to the 4DCT phase images. Results: Comparing initial plan to the dose accumulation: MIP-CT based GTV D98 degraded 2.42 Gy (60.10 Gy vs 57.68 Gy). Heart D1 increased 6.19 Gy (1.88 Gy vs 8.07 Gy); CTavg_tumor based GTV D98 degraded 0.34 Gy (60.07 Gy vs 59.73 Gy). Heart D1 increased 2.24 Gy (3.74 Gy vs $5.98 \mathrm{~Gy}$ ); CTavg_muscle based initial GTV D98 degraded 0.31 Gy (60.4 Gy vs 60.19 Gy). Heart D1 increased 3.44 Gy (4.38 Gy vs 7.82 Gy); CTavg_only based Initial GTV D98 degraded 6.63 Gy (60.11 Gy vs 53.48 Gy). Heart D1 increased $0.30 \mathrm{~Gy}$ ( $2.69 \mathrm{~Gy}$ vs $2.96 \mathrm{~Gy})$; in the presence of $\pm 3.5 \%$ range uncertainties, CTavg_tumor based plan's accumulated GTV D98 degraded to $57.99 \mathrm{~Gy}$ (+3.5\%) 59.38 Gy (-3.5\%), and CTavg_muscle based plan's accumulated GTV D98
\end{abstract}

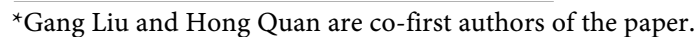


degraded to $59.37 \mathrm{~Gy}(+3.5 \%) 59.37 \mathrm{~Gy}(-3.5 \%)$. Conclusion: This study shows that CTavg_Tumor and CTavg_Muscle based planning strategies provide the most robust GTV coverage. However, clinicians need to be aware that the actual dose to OARs at distal end of target may increase. The study also indicates that the current SFUD PBS planning strategy might not be sufficient to compensate the CT calibration uncertainty.

\section{Keywords}

Proton Therapy, Single Field Uniform Dose, Pencil Beam Scanning, 4DCT, Lung Tumor

\section{Introduction}

Lung cancer is the leading cancer cause of death in the United States with over 158,000 estimated deaths in 2015 [1]. In the early 2000, several institutions have been investigating the benefits of using proton beam therapy for lung cancer based on PassiveScattering (PS) technique [2] [3]. After 2010, with the development of proton therapy technique, most of new proton centers under construction will be equipped with Pencil Beam Scanning (PBS) only. Moreover, some existing centers have been working on or plan to upgrade Passive-Scattering (PS) to PBS gantries. In contrast to more popularity of implementing the novel PBS technique in clinic, the treatment planning strategy for lung mobile tumors is still not clear due to the uncertainties related to the proton range and tumor motion. Recently, several institutions have started evaluating the interplay effect of motion target with spot scanning Intensity Modulated Proton Therapy (IMPT) delivery technique and robustness optimization algorithms to ensure the coverage for motion target [4]. But less effort has been put into the investigation of the dosimetric outcome and planning strategies of using Single Field Uniform Dose (SFUD) for mobile lung tumor which now has been one of the most popular proton PBS planning strategies implemented in clinic.

For motion management control, $4 \mathrm{D}$ computed tomography (4DCT) is widely used to access the internal organ motion [5]-[9]. Due to the heterogeneity density in the beam path and organ motion which will change the difference of the Water Effective Thickness (WET) from surface to the tumor during the breathing cycle, the proton plan calculated on the initial static planning CT could not represent the "actual" or accumulative dose. To ensure the target coverage in the presence of organ motion for the passive-scattering proton planning strategy, Lei et al. in 2007 suggested using CT-Avg with ICTV override to a higher density CT number (100 HU). However, passive-scanning proton planning workflow and consideration were very different from SFUD PBS planning because there is no aperture, compensator and smearing, etc. Lei's study did not include any proton range calibration uncertainties. Thus, to move clinical planning strategy from passive-scattering to PBS SFUD, it is very important to understand and evaluate benefits and risk of using different planning SFUD strategies.

However, artifacts resulting from the acquisition and post-processing limit 4DCT's 
accuracy. The artifacts present as artificial anatomic spatial distributions and cause uncertainty of the true anatomic position and configuration with breathing, potentially leading to errors in treatment planning delineation and targeting [10]. In this quantitative study, we created a series of virtual lung patient 4 DCT phase images to avoid any uncertainties in the target delineation and artifacts.

With the development of Deformable Imaging Registration (DIR), a new approach has been developed to assess the accumulate dose distribution using 4DCT to take into account of tumor and organ motion for each breathing phases [11]-[14]. The accumulated dose calculated based on the 4DCT DIR is representing the likely actual dose that would be delivered on the patient. In this study, we using different SFUD planning strategies and evaluate the actual accumulated dose distribution using DIR based on each breathing phase.

\section{Methods and Materials}

\subsection{Virtual Lung Tumor Patient 4DCT Model Generation}

The virtual lung tumor patient 4DCT model image sets include 11 CT images representing the target motion in SI direction with displacement $+/-5 \mathrm{~mm}$. The target volume and relative stopping power 0.91 of water for tumor density were acquired from the mean value for 10 lung patients measured in our institution, which was approximate to what was reported by other investigators [15]. The mechanics of respiration induces an expansion-contraction motion is the most significant in the superior-inferior (SI) direction of the patient [16] [17]. Due to the excursion of tumor motion for $90 \%$ lung patients was less than $10 \mathrm{~mm}$ [18], the target with $10 \mathrm{~mm}$ motion excursion was adopted in this study.

To generate the model, a patient $4 \mathrm{DCT}$ including 11 phase images with dimension $512 \times 512 \times 80$ and resolution $0.098 \mathrm{~cm} \times 0.098 \mathrm{~cm} \times 0.25 \mathrm{~cm}$ were adopted to perform simulation. First, each phase image was converted to the dimension $500 \times 500 \times 200$ with resolution $0.1 \mathrm{~cm} \times 0.1 \mathrm{~cm} \times 0.1 \mathrm{~cm}$ utilizing trilinear interpolation. Then all the phase images were sorted according to the displacement of diaphragm. It is reported that the spherical lesion was adopted in digital phantom for simulation. Similarly, a sphere with diameter of $3 \mathrm{~cm}$ representing target was inserted in the middle of right lung with relative proton stopping power of 0.91 water on Figure 1, which was a reference phase. The other 10 patient virtual 4DCT phase images were generated through inserting the target to cover region of target motion in SI direction with $-5 \mathrm{~mm}$ to 5 $\mathrm{mm}$ and resolution of $1 \mathrm{~mm}$ according to the reference image in different images with appropriate diaphragm displacement.

The gross tumor volume (GTV) on each phase image can be outlined accurately through threshold and ITV was acquired by combining GTVs from all the phases. Lung and heart were outlined on each phase phantom image as well. The average CT (CTavg_only) and maximum intensity projection (MIP) CT phantom image were generated by utilizing the mean and maximum CT numbers of the 11 phantom CT datasets at each pixel position respectively. The CTavg_only and MIP CT image represent the mean density and highest density in space in the process of all moving tissues among 

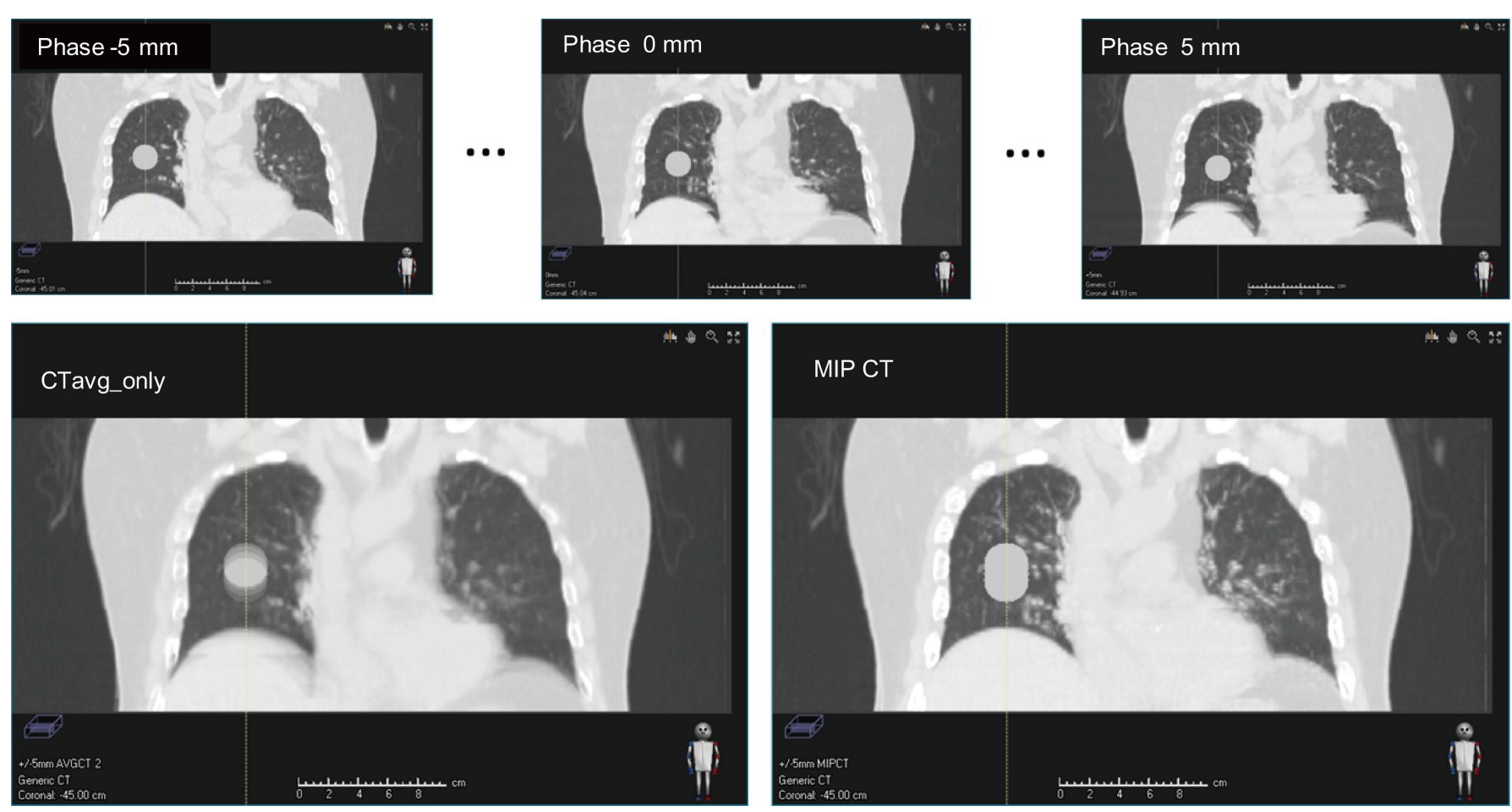

Figure 1. Phase image, CTavg_only and MIP CT.

the 11 phases of the motion cycle respectively. While the CTavg_muscle and CTavg_ tumor were generated through overriding ITV to muscle density and tumor density on average CT respectively. The contours including GTV, lung and heart in all the four kinds of average CT images are the same as the one on reference phase image.

\subsection{Proton Treatment Plan}

Single field uniform Dose (SFUD) proton plans were generated using posterior and right lateral beams. Plan was optimized based four initial CTs (MIP CT, CTavg_muscle, CTavg_tumor and CTavg_only) respectively. Posterior and Right lateral beams were chosen. Beam-specific PTVs (BSPTVs) were created to take into account of $3.5 \%+1$ $\mathrm{mm}$ proton range and energy selection uncertainty for each beam direction which is about $6 \mathrm{~mm}$ anterior/posterior for PA beam and $5 \mathrm{~mm}$ Left/Right for RT LAT beam direction. $5 \mathrm{~mm}$ margin was used for all around other direction from the ITV to BSPTV except distal end. Each field covers 95\% BSPTV with 60Gy and combines both field deliver $100 \%$ of the prescription dose to at least 95\% PTV_eval. However, in the current clinical practice, this BSPTV expansion methodology does not take into account for the WET changes between muscle and lung tissue. PTV_eval iscreated with 5 $\mathrm{mm}$ margin all around the ITV. The dose distribution of treatment plan based CTavg only was displayed on Figure 2 as an example.

\subsection{Plan Evaluation}

To calculate the "actual" or accumulative dose for a moving target, it is necessary to 


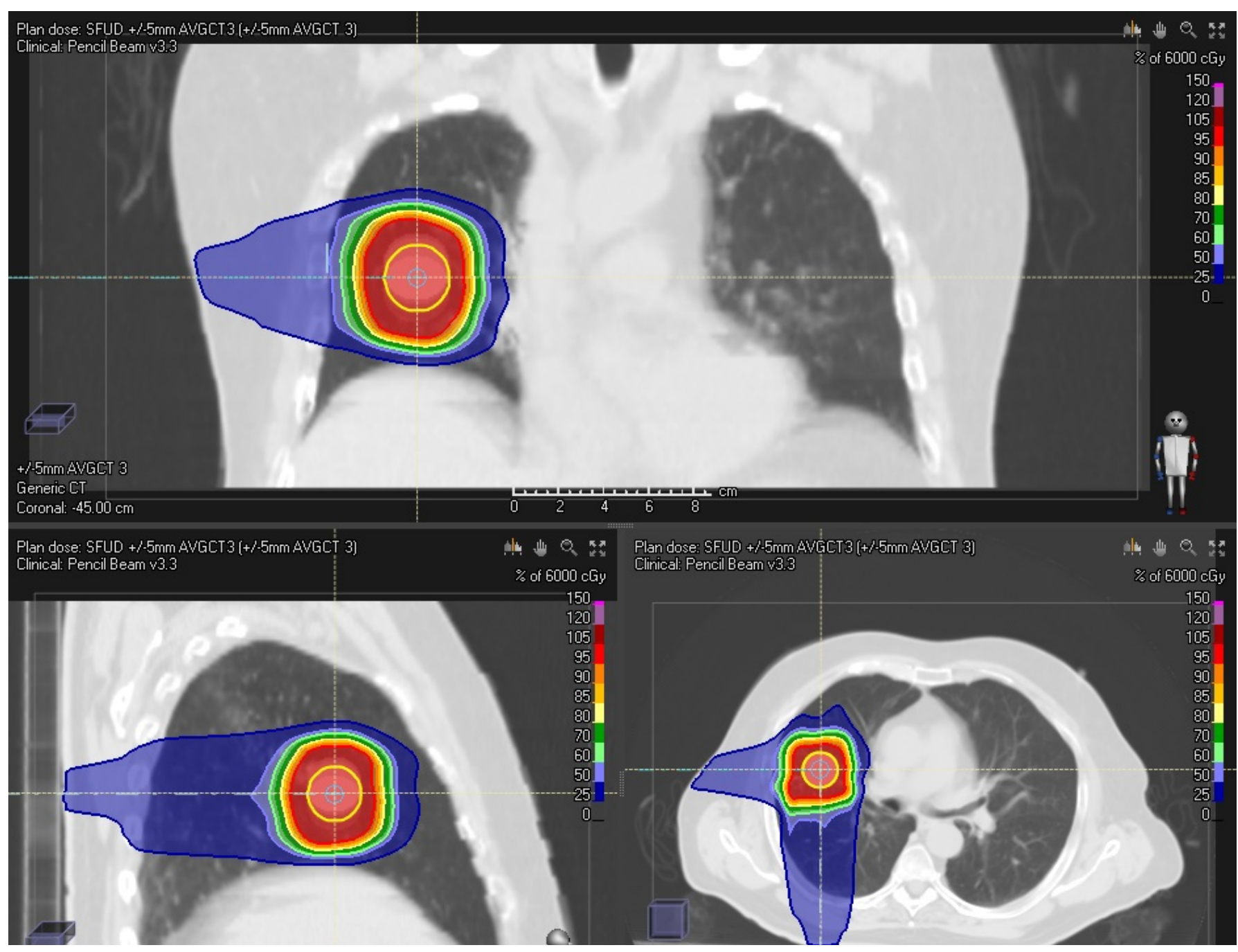

Figure 2. Dose distribution for initial plan based CTavg_only.

trace the voxel motion trajectory during the respiratory cycle. The voxel-by-voxel displacement vector linking the geometric coordinates between reference phase image and other phase images was acquired by the gray-scale image intensity-based, a kind of deformable image registration method [19]. Dose calculation was performed for each phase using the different initial plans respectively. Each phase dose distribution was deformed to the reference phase image using the corresponding displacement vector. The accumulative dose distribution of all 11 phases was equal weight summed onto the single reference phase. While the dose distribution calculated using the designing CT set for each plan was referred to as the initialize dose distribution for that treatment plan. The dose discrepancy of D99 D98 and D1 (the dose to $99 \%, 98 \%$ and $1 \%$ of region of interest volume, respectively) for target and D1 for heart between initial plan and phase dose, accumulative dose were calculated to analyze respectively.

When calculating cumulative dose distribution, we can pick any phase as a reference phase. In this study, the phase image with target position in the middle is adopted as 
reference. Because the target position in the other 10 phase images are symmetrical about the middle one, and an important factor is that the dose distribution in ITV for each initial plan is very homogenous. For example, in the initial plan based CTavg tumor, the D99, D98 and D1 of target are 60.3 Gy $\pm 0.07 \mathrm{~Gy}(1 \mathrm{SD}), 60.4 \mathrm{~Gy} \pm 0.01 \mathrm{~Gy}$ and $63.13 \mathrm{~Gy} \pm 0.1 \mathrm{~Gy}$ for all GTVs included in ITV respectively. The standard deviation is approximated to $0 \mathrm{~Gy}$, which demonstrates the dose distribution is most identify between GTVs included in ITV for initial plan based CTavg_tumor. The similar result can be acquired for initial plan based on other CT image.

\subsection{Proton Range Uncertainties $+/-3.5 \%$}

To assess the worst-case-scenario in presence of $+/-3.5 \%$ proton range difference due to the calibration challenge during the "actual" treatment, proton relative stopping power of each phase images were scaled up or down by $3.5 \%$ compared to the original clinical CT calibration curve. Then, dose recalculation and accumulation were performed based on the methods described above.

\section{Results}

Each phase dose distribution was acquired using the plan had been implemented on the designing CT set respectively. Figure 3 demonstrates the dose volume histogram (DVH) of GTV for each phase and initial plan. In the case of MIP CT and CTavg_only based planning, the dispersion of GTV's DVH is significantly larger comparing to the CTavg_tumor and CTavg_muscle based planning strategies which indicates lower dose delivered to target overall treatment due to using the inappropriate CT average image sets. The minimum of D98 for GTV reach $55.14 \mathrm{~Gy}$ in phase $5 \mathrm{~mm}$ and $47.51 \mathrm{~Gy}$ in phase $5 \mathrm{~mm}$ in the plan based MIP CT with initial GTV D98 $=60.09$ Gy and CTavg only with initial GTV D98 $=60.10$ Gy respectively. The dose difference on GTV was shown in Figure 4. While the worst case of D98 for GTV in the plan based CTavg tumor with initial GTV D98 $=60.07$ Gy and CTavg_muscle with initial GTV D98 = 60.4 Gy are 58.29 Gy and 59.31 Gy respectively. CTavg_muscle shows slightly better coverage in the worst-case breathing phase image set. Table 1 lists the detail result.

The accumulative dose was calculated by sum up total phase dose distribution using the corresponding DVF. The dose difference and DVH between accumulative dose and planned dose on target were shown in Figure 5. In fact, the D98 of cumulative dose for GTV based CTavg_only and MIP CT are 53.48 Gy and 57.68 Gy, the corresponding discrepancy compared to planned dose reach to $-11 \%$ and $-4 \%$ respectively. While the D98 of cumulative dose for GTV based CTavg_muscle and CTavg_tumor are acquired as 60.19 Gy with discrepancy $0 \%$ and 59.73 Gy with discrepancy $-1 \%$, which is close to the initial plan dose. The dose discrepancy on GTV between cumulative dose and initial dose are larger for MIP CT and CTavg_only sensitivity of proton range and motion of the tumor uncertainties. While the corresponding discrepancy are relatively small for CTavg_muscle and CTavg_tumor, which is the reason that the proton plan was often implemented on CTavg_muscle or CTavg_tumor in most of the proton clinic. 


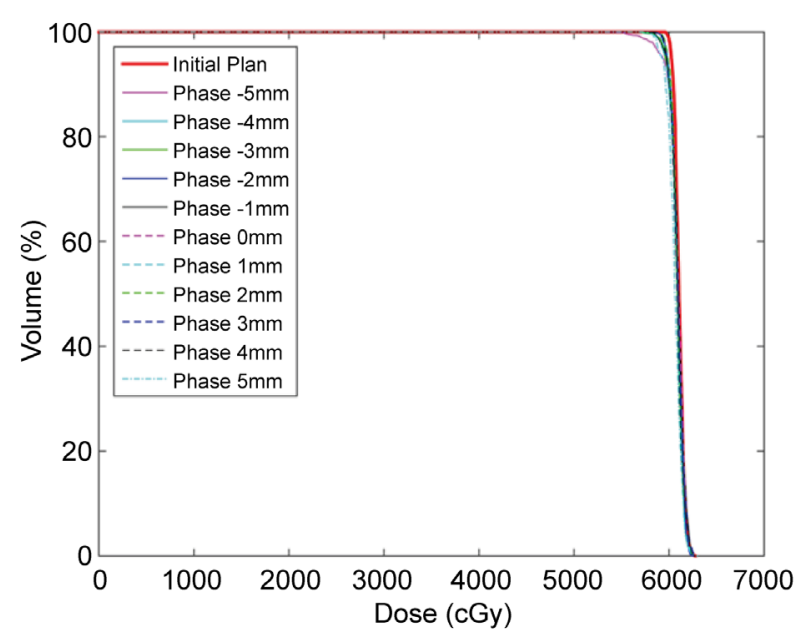

(a)

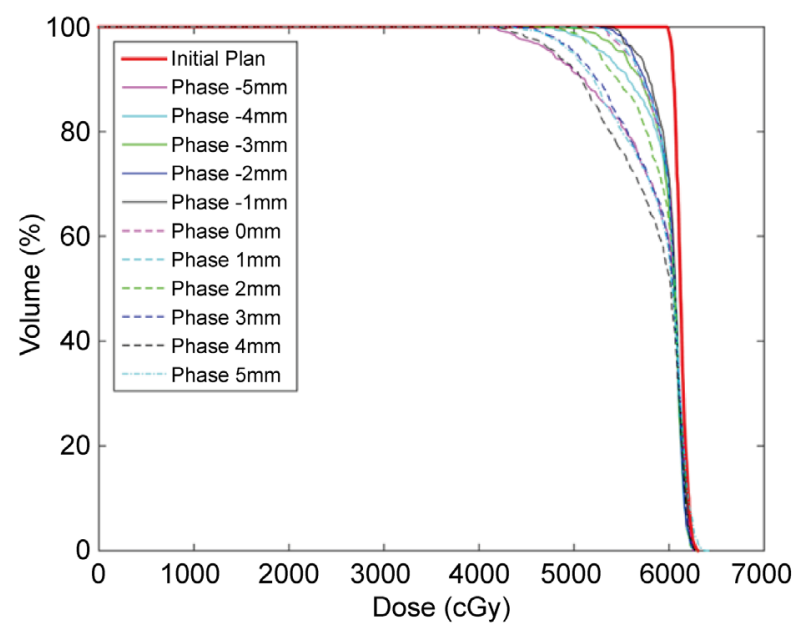

(c)

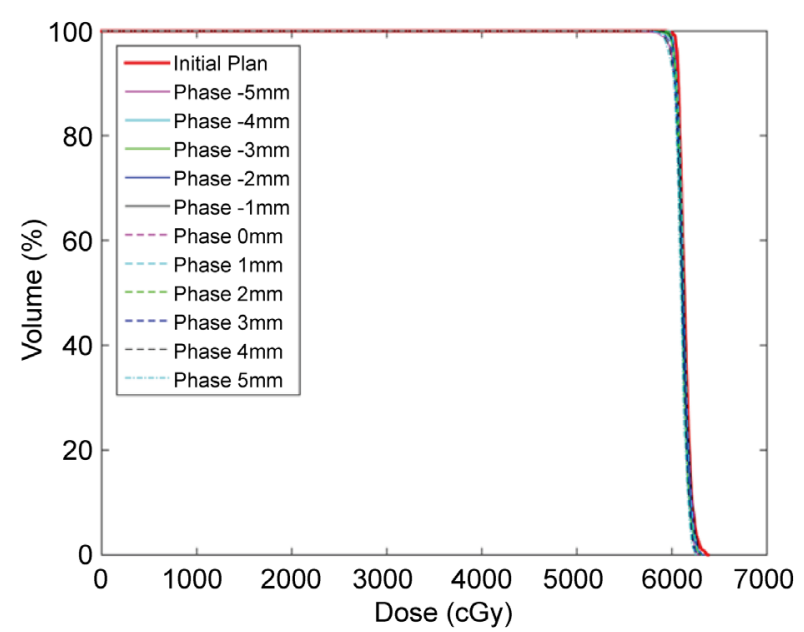

(b)

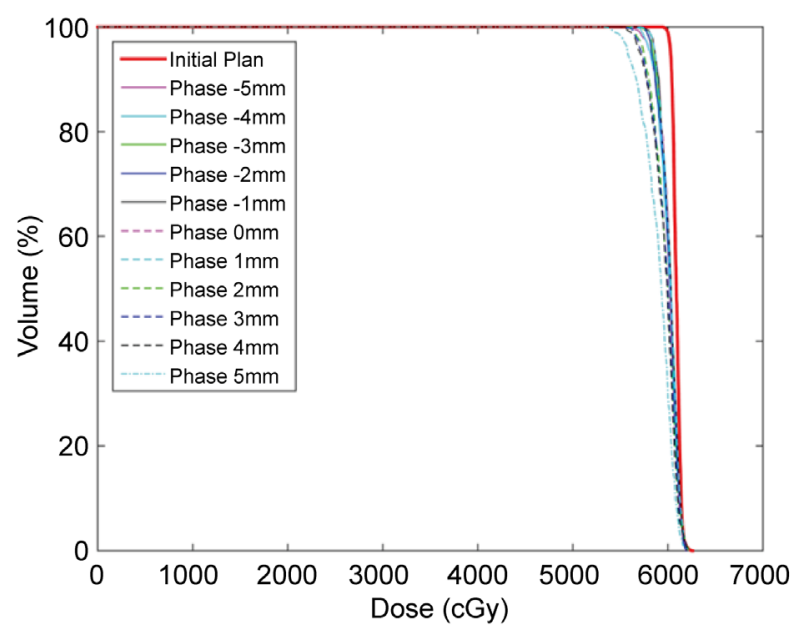

(d)

Figure 3. DVHs of different phase for GTV and initial plan based (a) CTavg_tumor, (b) CTavg_muscle, (c) CTavg_only, (d) MIPCT.

However, in presence of proton range uncertainty of $+/-3.5 \%$ [20] [21], the dispersion of DVHs significantly increase based both CTavg_tumor and CTavg_muscle. DVH for GTV on each phase was displayed on Figure 6. In the worst case, GTV D98 decrease to $51.96 \mathrm{~Gy}$ in phase $-5 \mathrm{~mm}$ on CTavg_tumor based plan, while D98 of GTV decrease to $55.96 \mathrm{~Gy}$ in phase $-5 \mathrm{~mm}$ on CTavg_muscle based plan. Detail result was listed in Table 2. Figure 7 shows the GTV coverage difference between the accumulative dose and planned dose.

As far as heart, the D1 are $1.88 \mathrm{~Gy}, 2.69 \mathrm{~Gy}, 3.74 \mathrm{~Gy}$ and $4.38 \mathrm{~Gy}$ in the initial plan based on MIP CT, CTavg_only, CTavg_tumor and CTavg_muscle respectively. But the D1 for heart reaches to $8.02 \mathrm{~Gy}$ on phase $-5 \mathrm{~mm}$ on CTavg_tumor based plan, while the one is $10.21 \mathrm{~Gy}$ on phase $-5 \mathrm{~mm}$ on CTavg_muscle based plan. The worst case dose difference in heart for plan based on CTavg_tumor and CTavg_muscle were shown in Figure 4. The accumulative dose through breathing phases are 8.07 Gy (+6.19 Gy), 2.96 Gy (+0.27 Gy), 5.98 Gy (+2.24 Gy) and 7.82 Gy (+3.44 Gy) for initial plan based on 


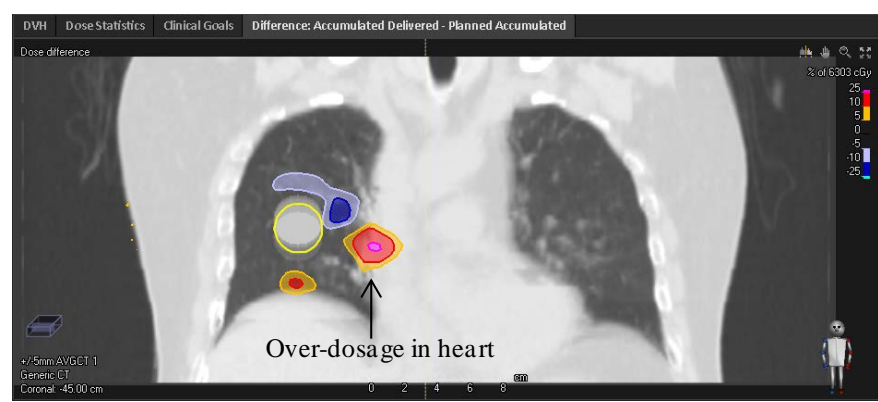

(a)

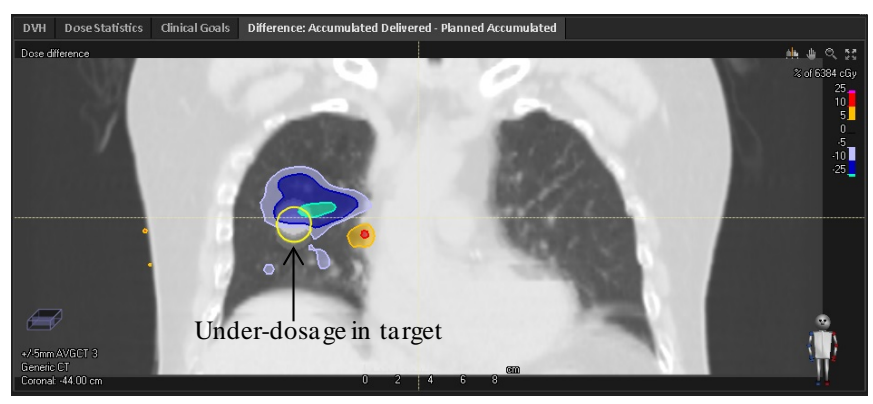

(c)

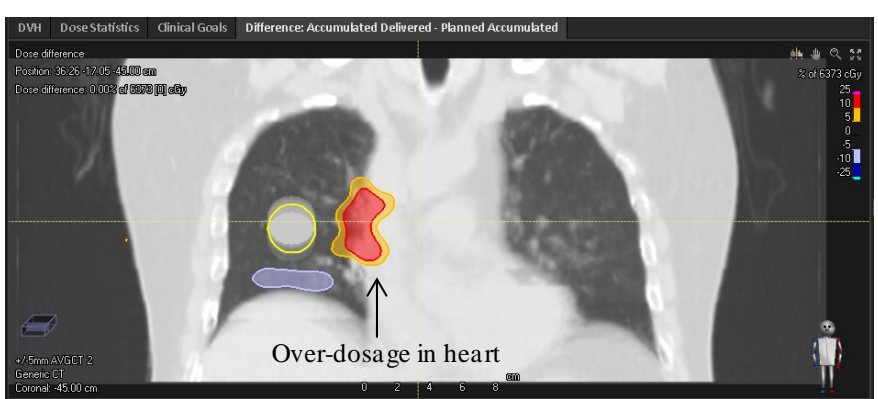

(b)

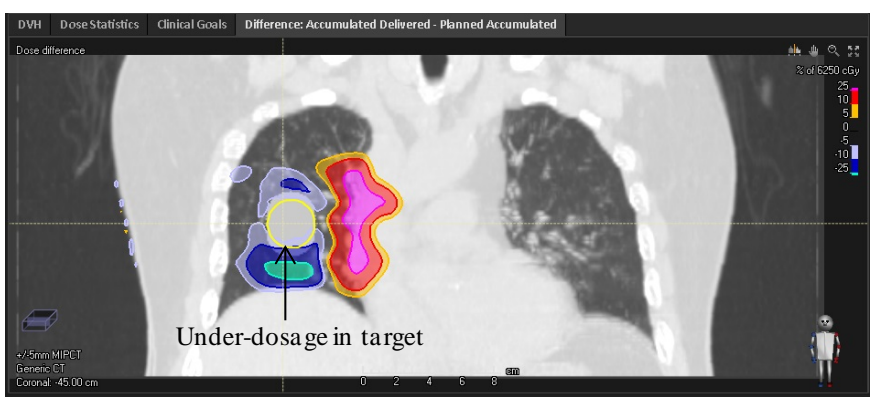

(d)

Figure 4. Dose difference (a) between initial plan based CTavg_tumor and on phase $-5 \mathrm{~mm}$ for heart, (b) between initial plan based CTavg_muscle and phase $-5 \mathrm{~mm}$ for heart, (c) between initial plan based CTavg_only and phase $5 \mathrm{~mm}$ for target, (d) between initial plan based MIP CT and phase $5 \mathrm{~mm}$ for target.

MIP CT, CTavg_only, CTavg_tumor and CTavg_muscle respectively (compared to the initial plan). The results indicate that overriding ITV density could improve the target coverage. However, as a tradeoff, proton dose might stop into the heart at the distal end of the target.

\section{Discussion}

The study shows that the proton dose on the static CT might not be equal to the accumulative or actual delivered dose due to the motion and uncertainties. Normally, accumulative dose to GTV will degraded compared to the initial plan. The study also demonstrated that the $4 \mathrm{DCT}$ images combined with deformable image registration could be a very useful tool to assess the "actual" treatment delivered dose. The result shows that CTavg_tumor and CTavg_muscle are the two most robust proton SFUD plan techniques for lung mobile tumor which agrees with the finding from Kang et al on Passive Scattering proton planning strategies [22].

Large proton dose uncertainties were observed in the distal end of the mobile target on MIP CT, CTavg_tumor and CTavg_muscle. This could be explained by the overestimate the tumor density in the initial planning CT. When tumor is moving in and out during the breathing cycle, proton beam will stop further than the initial plan which result more accumulative dose to the heart at the distal end of target. In the presence of CT calibration uncertainty $+/-3.5 \%$, all four planning strategies are not able of provide adequate target coverage during the breathing cycle, because BSPTV $5 \sim 6 \mathrm{~mm}$ along 
Table 1. Dose value of GTV and Heart for initial plan based (a) CTavg_tumor, (b) CTavg_ muscle, (c) CTavg_only, (d) MIP CT.

(a)

\begin{tabular}{|c|c|c|c|c|}
\hline & \multicolumn{3}{|c|}{ GTV } & \multirow{3}{*}{$\begin{array}{c}\text { Heart } \\
\text { D1 } \\
\text { Gy }\end{array}$} \\
\hline & D99 & D98 & D1 & \\
\hline & Gy & Gy & Gy & \\
\hline Initial Plan & 59.94 & 60.07 & 62.34 & 3.74 \\
\hline Phase $-5 \mathrm{~mm}$ & 57.01 & 58.29 & 62.15 & 8.02 \\
\hline Phase $-4 \mathrm{~mm}$ & 58.63 & 59.12 & 62.13 & 7.20 \\
\hline Phase $-3 \mathrm{~mm}$ & 58.81 & 59.22 & 62.14 & 6.86 \\
\hline Phase $-2 \mathrm{~mm}$ & 59.23 & 59.51 & 62.09 & 6.54 \\
\hline Phase $-1 \mathrm{~mm}$ & 58.79 & 59.13 & 62.35 & 5.08 \\
\hline Phase $0 \mathrm{~mm}$ & 59.20 & 59.48 & 62.36 & 4.80 \\
\hline Phase $1 \mathrm{~mm}$ & 59.12 & 59.39 & 62.25 & 4.97 \\
\hline Phase $2 \mathrm{~mm}$ & 59.40 & 59.59 & 62.33 & 7.73 \\
\hline Phase $3 \mathrm{~mm}$ & 59.23 & 59.45 & 62.46 & 7.44 \\
\hline Phase $4 \mathrm{~mm}$ & 59.36 & 59.50 & 62.35 & 7.36 \\
\hline Phase $5 \mathrm{~mm}$ & 58.43 & 58.70 & 62.18 & 7.02 \\
\hline Accumulation & 59.30 & 59.73 & 61.78 & 5.98 \\
\hline Deviation* & $-1 \%$ & $-1 \%$ & $-1 \%$ & $60 \%$ \\
\hline
\end{tabular}

(b)

\begin{tabular}{ccccc}
\hline & & GTV & Heart \\
\cline { 2 - 4 } & D99 & D98 & D1 & D1 \\
\hline Initial Plan & 60.34 & Gy & Gy & Gy \\
Phase $-5 \mathrm{~mm}$ & 58.96 & 59.46 & 63.17 & 10.21 \\
Phase $-4 \mathrm{~mm}$ & 59.56 & 59.91 & 62.45 & 9.37 \\
Phase $-3 \mathrm{~mm}$ & 59.72 & 60.04 & 62.76 & 8.80 \\
Phase $-2 \mathrm{~mm}$ & 59.82 & 60.08 & 62.75 & 8.22 \\
Phase $-1 \mathrm{~mm}$ & 59.79 & 59.96 & 62.76 & 6.76 \\
Phase $0 \mathrm{~mm}$ & 60.07 & 60.18 & 62.73 & 6.45 \\
Phase $1 \mathrm{~mm}$ & 60.06 & 60.18 & 62.71 & 6.66 \\
Phase $2 \mathrm{~mm}$ & 59.96 & 59.99 & 62.61 & 10.14 \\
Phase $3 \mathrm{~mm}$ & 59.35 & 59.71 & 62.43 & 9.78 \\
Phase $4 \mathrm{~mm}$ & 59.16 & 59.50 & 62.33 & 9.59 \\
Phase $5 \mathrm{~mm}$ & 58.95 & 59.32 & 62.32 & 9.21 \\
Accumulation & 60.06 & 60.19 & 61.97 & 7.82 \\
Deviation & $0 \%$ & $0 \%$ & $-2 \%$ & $79 \%$ \\
\hline
\end{tabular}


(c)

\begin{tabular}{|c|c|c|c|c|}
\hline & \multicolumn{3}{|c|}{ GTV } & \multirow{3}{*}{$\begin{array}{c}\text { Heart } \\
\text { D1 } \\
\text { Gy }\end{array}$} \\
\hline & D99 & D98 & D1 & \\
\hline & Gy & Gy & Gy & \\
\hline Initial Plan & 59.98 & 60.11 & 62.72 & 2.69 \\
\hline Phase $-5 \mathrm{~mm}$ & 42.99 & 43.97 & 62.32 & 3.96 \\
\hline Phase $-4 \mathrm{~mm}$ & 49.27 & 50.74 & 62.36 & 3.76 \\
\hline Phase $-3 \mathrm{~mm}$ & 51.74 & 52.79 & 62.33 & 3.48 \\
\hline Phase $-2 \mathrm{~mm}$ & 54.27 & 55.15 & 62.30 & 3.32 \\
\hline Phase $-1 \mathrm{~mm}$ & 54.81 & 55.07 & 62.44 & 1.87 \\
\hline Phase $0 \mathrm{~mm}$ & 53.55 & 54.00 & 62.53 & 1.76 \\
\hline Phase $1 \mathrm{~mm}$ & 53.64 & 54.18 & 62.22 & 1.91 \\
\hline Phase $2 \mathrm{~mm}$ & 49.62 & 50.92 & 62.25 & 4.53 \\
\hline Phase $3 \mathrm{~mm}$ & 46.66 & 47.98 & 62.36 & 4.44 \\
\hline Phase $4 \mathrm{~mm}$ & 43.53 & 44.96 & 62.50 & 4.44 \\
\hline Phase $5 \mathrm{~mm}$ & 46.50 & 47.51 & 63.13 & 3.96 \\
\hline Accumulation & 52.87 & 53.48 & 61.87 & 2.96 \\
\hline Deviation* & $-12 \%$ & $-11 \%$ & $-1 \%$ & $10 \%$ \\
\hline
\end{tabular}

(d)

\begin{tabular}{|c|c|c|c|c|}
\hline & \multicolumn{3}{|c|}{ GTV } & \multirow{3}{*}{$\begin{array}{c}\text { Heart } \\
\text { D1 } \\
\text { Gy }\end{array}$} \\
\hline & D99 & D98 & D1 & \\
\hline & Gy & Gy & Gy & \\
\hline Initial Plan & 59.99 & 60.10 & 61.94 & 1.88 \\
\hline Phase $-5 \mathrm{~mm}$ & 57.04 & 57.38 & 61.77 & 12.79 \\
\hline Phase $-4 \mathrm{~mm}$ & 57.27 & 57.50 & 61.76 & 12.10 \\
\hline Phase $-3 \mathrm{~mm}$ & 57.82 & 57.99 & 61.74 & 11.67 \\
\hline Phase $-2 \mathrm{~mm}$ & 57.78 & 58.02 & 61.75 & 11.07 \\
\hline Phase $-1 \mathrm{~mm}$ & 58.07 & 58.35 & 61.85 & 8.94 \\
\hline Phase $0 \mathrm{~mm}$ & 58.02 & 58.32 & 61.88 & 8.44 \\
\hline Phase $1 \mathrm{~mm}$ & 58.02 & 58.35 & 61.93 & 8.94 \\
\hline Phase $2 \mathrm{~mm}$ & 56.53 & 56.77 & 61.97 & 12.93 \\
\hline Phase $3 \mathrm{~mm}$ & 56.38 & 56.65 & 61.94 & 12.66 \\
\hline Phase $4 \mathrm{~mm}$ & 56.14 & 56.51 & 61.91 & 12.36 \\
\hline Phase $5 \mathrm{~mm}$ & 54.39 & 55.15 & 61.60 & 11.58 \\
\hline Accumulation & 57.48 & 57.68 & 61.36 & 8.07 \\
\hline Deviation ${ }^{\star}$ & $-4 \%$ & $-4 \%$ & $-1 \%$ & $329 \%$ \\
\hline
\end{tabular}

Abbreviations: GTV = gross tumor volume; D99 D98 and D1 (the dose to 99\%, $98 \%$ and $1 \%$ of region of interest volume, respectively); ${ }^{\star}$ Deviation represents the deviation between accumulation and initial plan indicated as proportion of initial plan. Accumulation represents the accumulative dose of eleven phases. 


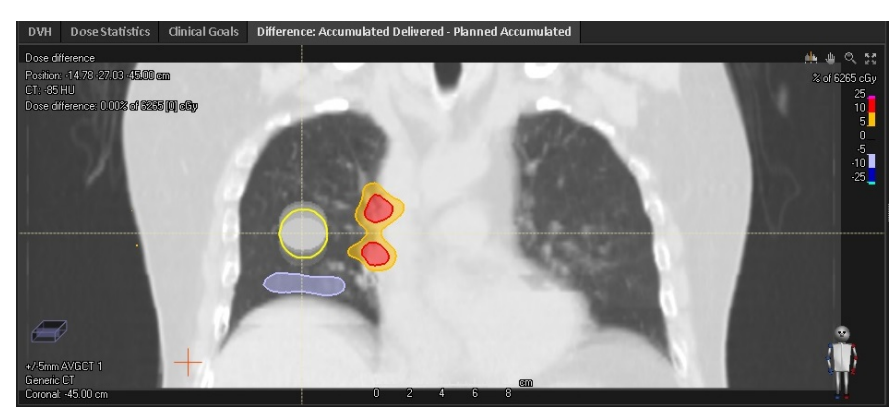

(a1)

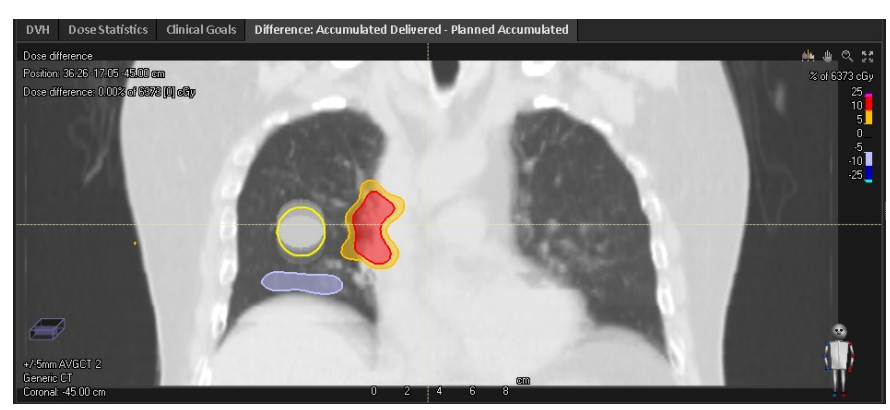

(b1)

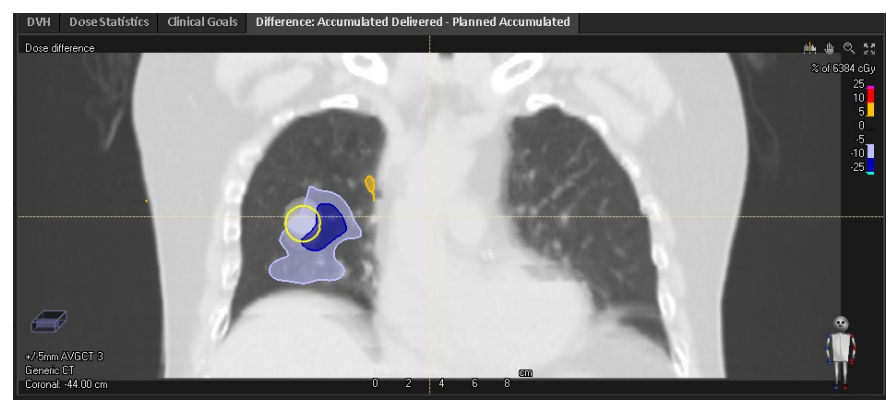

(c1)

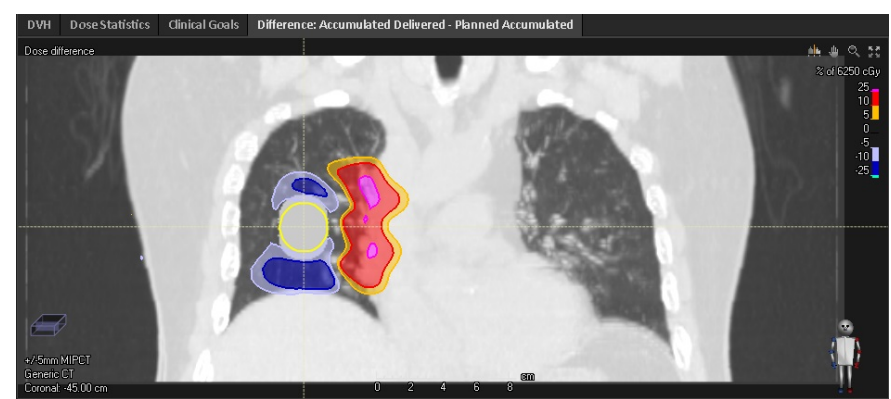

$(\mathrm{d} 1)$

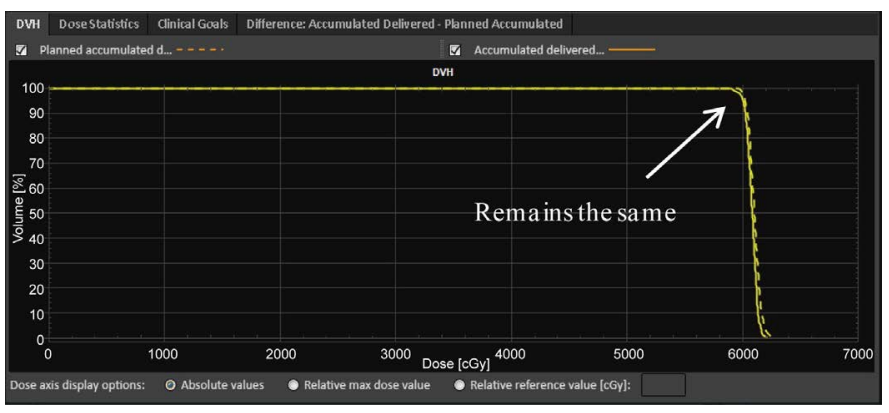

(a2)

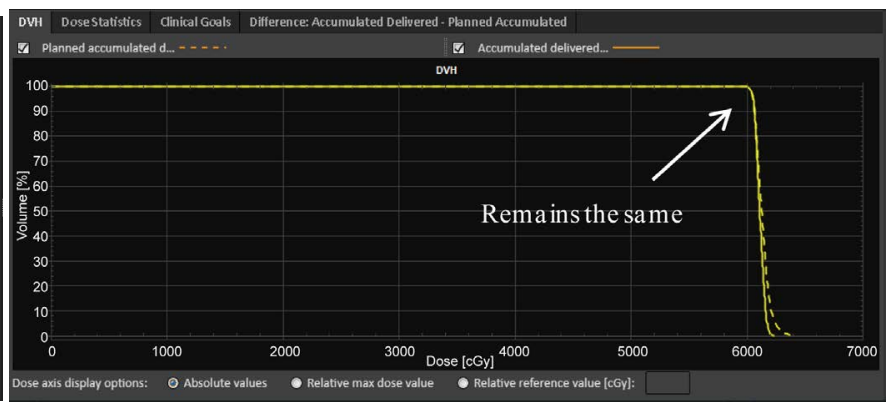

(b2)

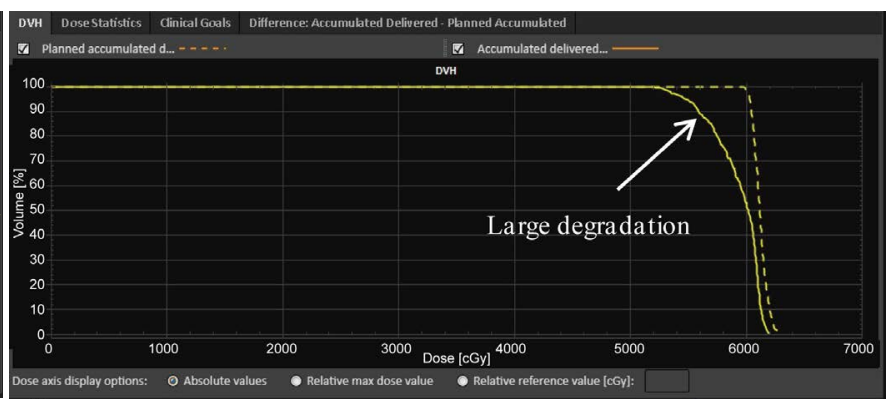

(c2)

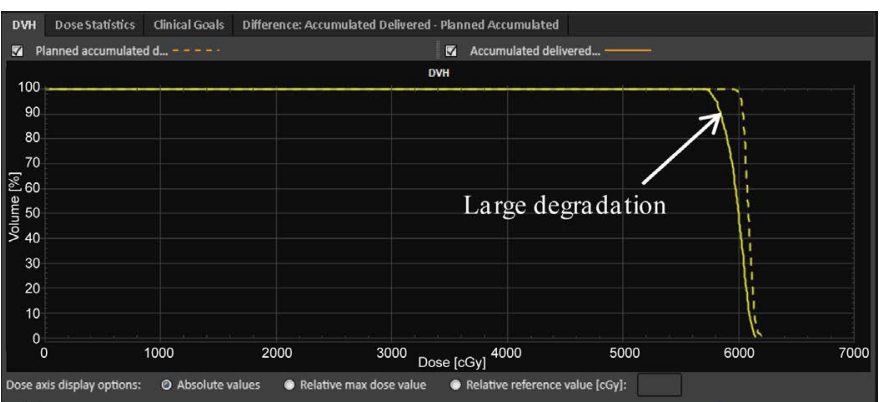

$(\mathrm{d} 2)$

Figure 5. Dose difference between accumulation and initial plan based on (a1) CTavg_tumor, (b1) CTavg_muscle, (c1) CTavg_only, (d1) MIP, GTV comparison DVH between accumulation and initial plan based on (a2) CTavg_tumor, (b2) CTavg_muscle, (c2) CTavg_only, (d2) MIP CT.

the beam direction doesn't take into account of the tissue heterogeneity in the lung region especially around bone, muscle and lung tissue interface. More recently, Liu et al. have been working worst-case scenario optimized treatment plan for lung cancer for 


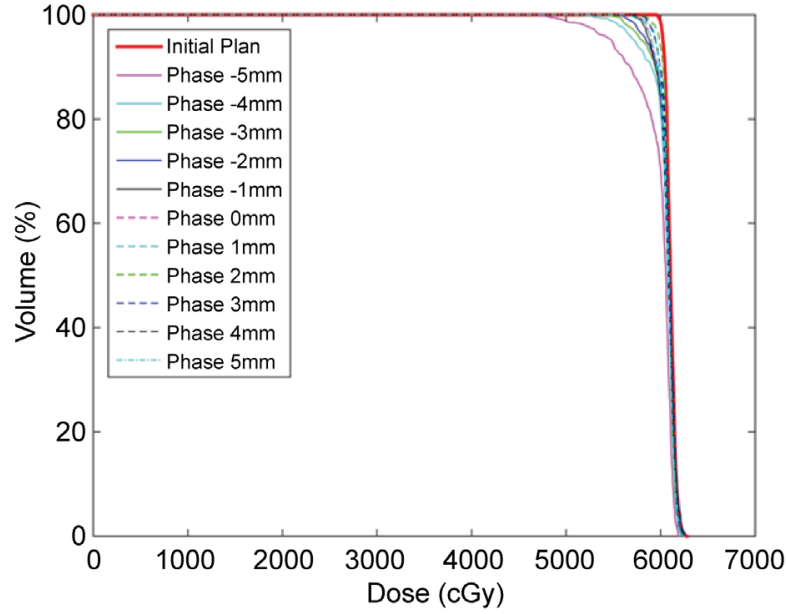

(a)

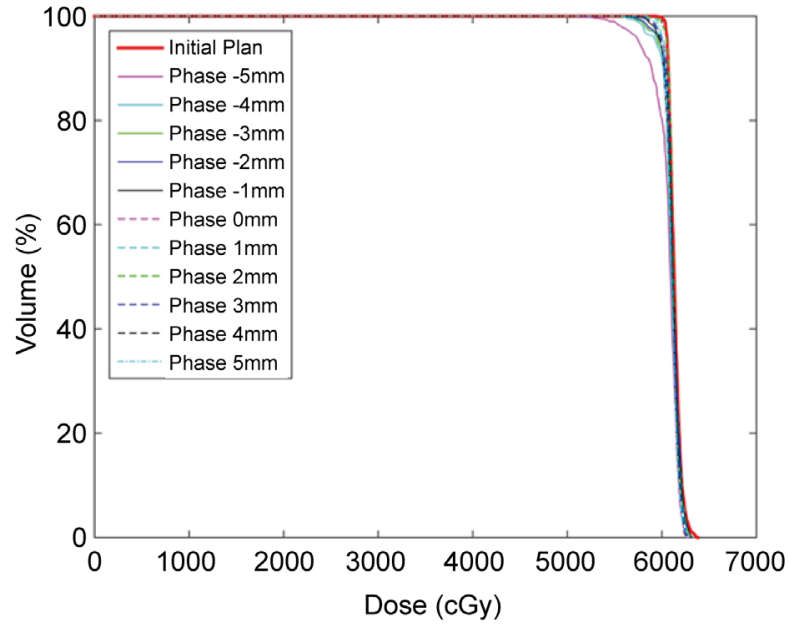

(c)

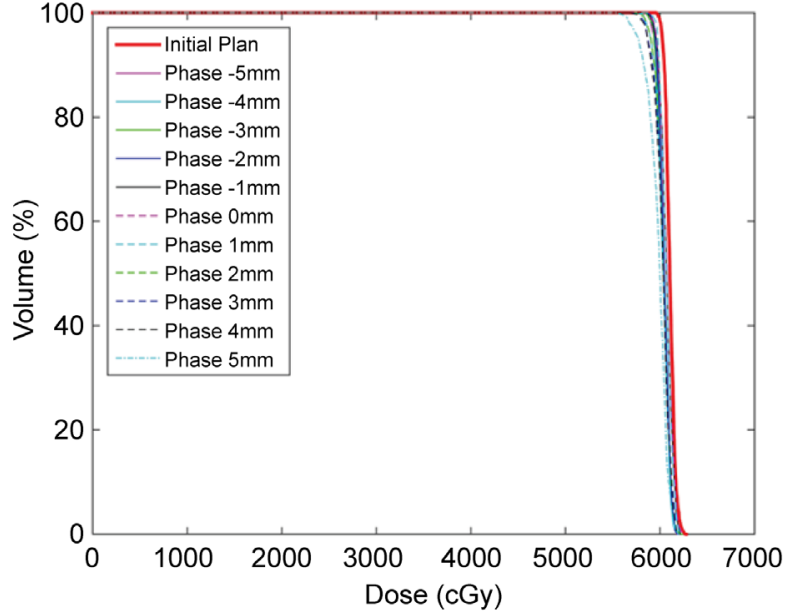

(b)

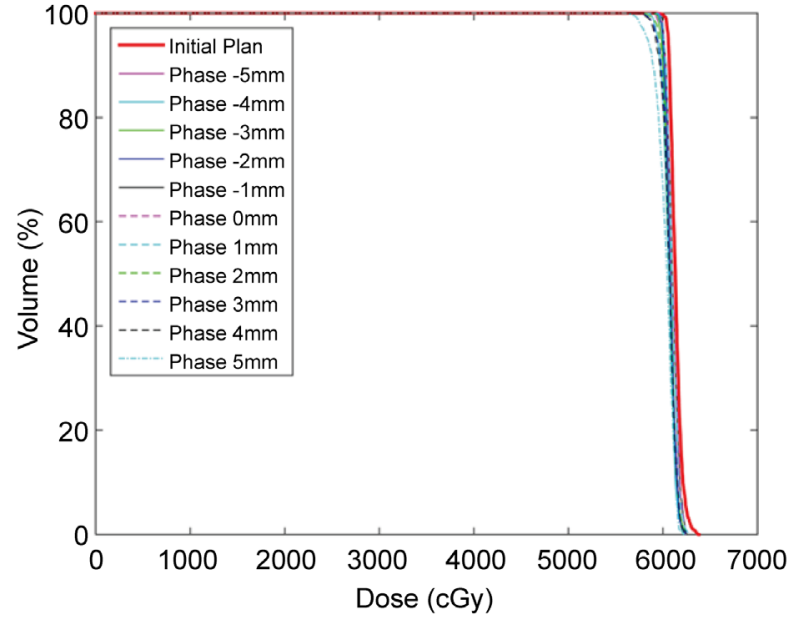

(d)

Figure 6. DVHs of different phase for GTV with initial pan based (a) CTavg_tumor considering 3.5\% proton range overestimate, (b) CTavg_tumor considering 3.5\% proton range underestimate, (c) CTavg_muscle considering 3.5\% proton range overestimate, (d) CTavg_ muscle considering $3.5 \%$ proton range underestimate.

intensity modulated proton therapy (IMPT) which shows improved dose coverage compared to the PTV based IMPT plan.

Last but not least, there is still limitation on this method of using DIR and 4DCT to assess the actual dose to the mobile target. Because the interplay effect between the proton scanning beam delivery and target or organ motion may cause inhomogeneous dose distribution. Current methodology assumes that all the proton dose were totally delivered to each phases, but in reality some spots and energy layers might be delivered in one phase while others might be delivered to the other phases. Thus, the accumulative or actual dose might be different. Dose painting technique was suggested to minimize the interplay effects.

\section{Conclusion}

This study quantitatively evaluates the advantage and disadvantage of four different 
Table 2. Dose value of GTV with initial plan based (a) CTavg_tumor considering 3.5\% proton range overestimate, (b) CTavg_tumor considering 3.5\% proton range underestimate, (c) CTavg muscle considering $3.5 \%$ proton range overestimate, (d) based CTavg_muscle considering 3.5\% proton range underestimate.

(a)

\begin{tabular}{cccc}
\hline & & GTV & \\
\cline { 2 - 4 } & D99 & D 98 & D 1 \\
Gy & Gy & Gy \\
\hline Initial Plan & 59.94 & 60.07 & 62.34 \\
Phase $-5 \mathrm{~mm}$ & 49.83 & 51.96 & 61.80 \\
Phase $-4 \mathrm{~mm}$ & 54.57 & 55.53 & 62.05 \\
Phase $-3 \mathrm{~mm}$ & 55.94 & 56.44 & 62.07 \\
Phase $-2 \mathrm{~mm}$ & 56.74 & 57.37 & 62.00 \\
Phase $-1 \mathrm{~mm}$ & 57.95 & 58.18 & 62.28 \\
Phase $0 \mathrm{~mm}$ & 58.20 & 58.40 & 62.18 \\
Phase $1 \mathrm{~mm}$ & 58.21 & 58.50 & 62.04 \\
Phase $2 \mathrm{~mm}$ & 59.04 & 59.41 & 62.21 \\
Phase $3 \mathrm{~mm}$ & 58.58 & 58.88 & 62.41 \\
Phase $4 \mathrm{~mm}$ & 58.52 & 58.87 & 62.21 \\
Phase $5 \mathrm{~mm}$ & 57.73 & 58.99 & 62.08 \\
Accumulation & 57.80 & 57.99 & 61.67 \\
Deviation & $-4 \%$ & $-3 \%$ & $-1 \%$ \\
\hline
\end{tabular}

(b)

\begin{tabular}{cccc}
\hline & & GTV & \\
\cline { 2 - 4 } & D99 & D98 & D1 \\
& Gy & Gy & Gy \\
\hline Initial Plan & 59.94 & 60.07 & 62.34 \\
Phase $-5 \mathrm{~mm}$ & 58.95 & 59.02 & 61.54 \\
Phase $-4 \mathrm{~mm}$ & 58.33 & 58.56 & 61.51 \\
Phase $-3 \mathrm{~mm}$ & 58.83 & 59.10 & 61.70 \\
Phase $-2 \mathrm{~mm}$ & 59.17 & 59.32 & 61.55 \\
Phase $-1 \mathrm{~mm}$ & 59.06 & 59.22 & 62.03 \\
Phase $0 \mathrm{~mm}$ & 59.16 & 59.37 & 62.18 \\
Phase $1 \mathrm{~mm}$ & 59.35 & 59.62 & 61.96 \\
Phase $2 \mathrm{~mm}$ & 58.40 & 58.59 & 61.69 \\
Phase $3 \mathrm{~mm}$ & 58.05 & 58.42 & 61.72 \\
Phase $4 \mathrm{~mm}$ & 57.94 & 58.25 & 61.71 \\
Phase $5 \mathrm{~mm}$ & 56.53 & 56.76 & 61.61 \\
Accumulation & 59.25 & 59.38 & 61.34 \\
Deviation & $-1 \%$ & $-1 \%$ & $-2 \%$ \\
\hline
\end{tabular}


(c)

\begin{tabular}{cccc}
\hline & & GTV & \\
\cline { 2 - 4 } & D 99 & D98 & D1 \\
\hline Initial Plan & 60.34 & Gy & 63.17 \\
Phase $-5 \mathrm{~mm}$ & 54.96 & 60.40 & 62.33 \\
Phase $-4 \mathrm{~mm}$ & 57.40 & 55.75 & 62.78 \\
Phase $-3 \mathrm{~mm}$ & 57.86 & 58.00 & 62.83 \\
Phase $-2 \mathrm{~mm}$ & 58.09 & 58.23 & 62.79 \\
Phase $-1 \mathrm{~mm}$ & 58.57 & 58.52 & 62.92 \\
Phase $0 \mathrm{~mm}$ & 59.11 & 59.20 & 62.81 \\
Phase $1 \mathrm{~mm}$ & 59.20 & 59.39 & 62.72 \\
Phase $2 \mathrm{~mm}$ & 59.95 & 59.47 & 62.78 \\
Phase $3 \mathrm{~mm}$ & 58.83 & 60.12 & 62.53 \\
Phase $4 \mathrm{~mm}$ & 58.80 & 59.35 & 62.47 \\
Phase $5 \mathrm{~mm}$ & 59.53 & 59.16 & 62.59 \\
Accumulation & 58.97 & 59.75 & 62.15 \\
Deviation & $-2 \%$ & 59.37 & $-2 \%$ \\
\hline
\end{tabular}

(d)

\begin{tabular}{cccc}
\hline & & GTV & \\
\cline { 2 - 4 } & D 99 & D98 & D1 \\
\hline Initial Plan & 60.34 & Gy & 63.17 \\
Phase $-5 \mathrm{~mm}$ & 59.36 & 60.40 & 62.14 \\
Phase $-4 \mathrm{~mm}$ & 58.97 & 59.58 & 62.01 \\
Phase $-3 \mathrm{~mm}$ & 59.50 & 59.11 & 62.24 \\
Phase $-2 \mathrm{~mm}$ & 59.66 & 59.59 & 62.13 \\
Phase $-1 \mathrm{~mm}$ & 59.92 & 59.82 & 62.34 \\
Phase $0 \mathrm{~mm}$ & 59.88 & 59.99 & 62.40 \\
Phase $1 \mathrm{~mm}$ & 59.80 & 59.97 & 62.42 \\
Phase $2 \mathrm{~mm}$ & 58.99 & 59.93 & 62.10 \\
Phase $3 \mathrm{~mm}$ & 58.53 & 59.34 & 62.10 \\
Phase $4 \mathrm{~mm}$ & 58.54 & 58.98 & 62.07 \\
Phase $5 \mathrm{~mm}$ & 57.30 & 58.78 & 61.69 \\
Accumulation & 58.91 & 57.56 & 61.65 \\
Deviation & $-2 \%$ & 59.29 & $-2 \%$ \\
\hline
\end{tabular}

Abbreviations: GTV = gross tumor volume; D99 D98 and D1 (the dose to 99\%, 98\% and 1\% of region of interest volume, respectively); ${ }^{\star}$ Deviation represents the deviation between accumulation and initial plan indicated as proportion of initial plan. Accumulation represents the accumulative dose of eleven phases. 


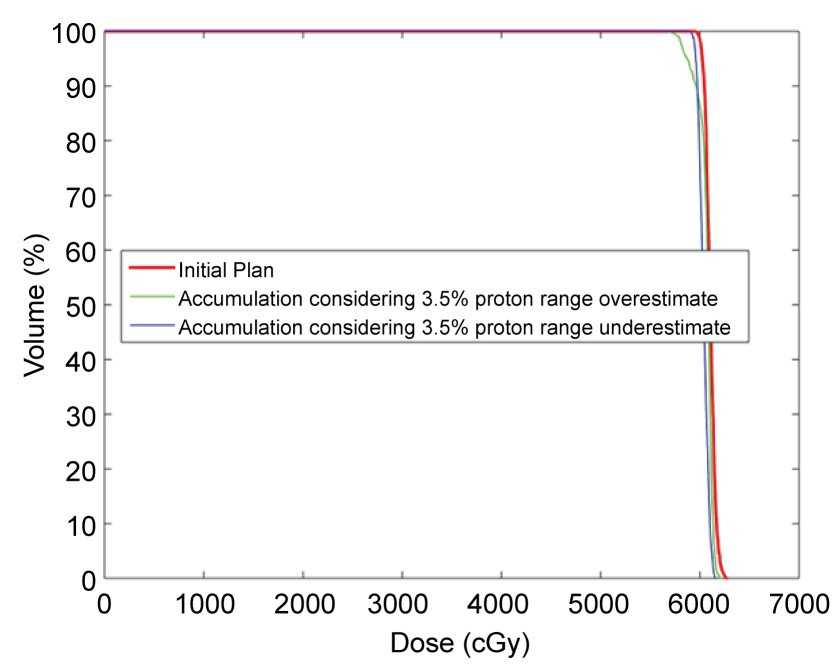

(a)

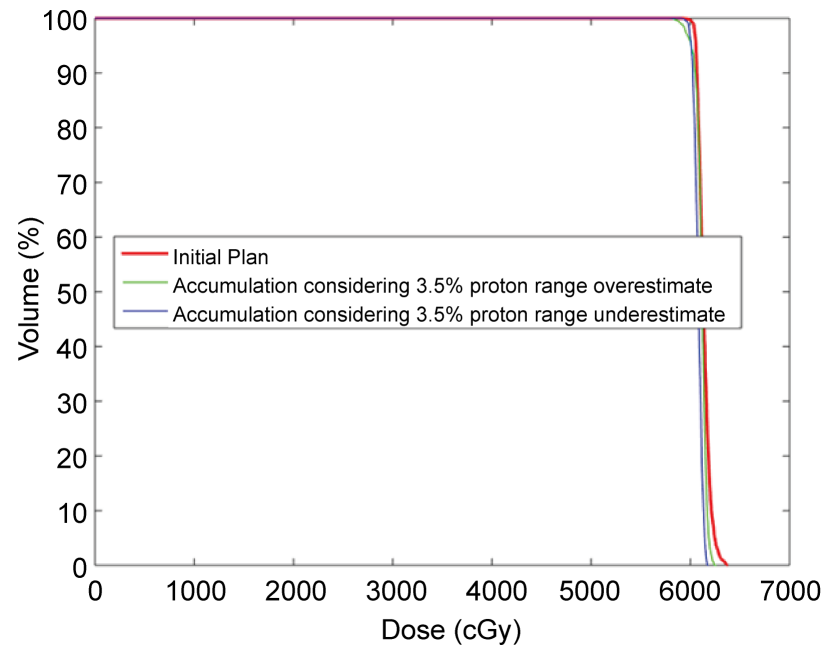

(b)

Figure 7. Comparison of DVHs for GTV between accumulation and initial plan based (a) CTavg_tumor, (b) CTavg_muscle.

SFUD PBS planning strategies for lung mobile tumor. The study recommends using CTavg_tumor and CTavg_muscle SFDU planning strategies for mobile lung tumor. Our study results also indicate that the more conservative in overriding the ITV density to high density will result in more significant overdose of the organ at the distal end of the target. Special care is needed in evaluating the cases where lung and heart dose is critical. Last but not the least, all of the four planning strategies in study do not compensate adequately the proton range uncertainty in lung tissue (3.5\%). Additional BSPTV margins might be needed along the beam direction in the lung tissue. Thus, SFUD PBS planning strategy based on CTavg_tumor and CTavg_muscle is not perfect solutions to mobile lung tumor due to uncertainty in the interplay effect and proton range uncertainties. The future planning strategy for lung mobile tumor will go towards the development of robustness optimization algorithm, repainting technique as well as motion management of using gating or breath-hold.

\section{References}

[1] Siegel, R.L., Miller, K.D. and Jemal, A. (2015) Cancer Statistics, 2015. CA: A Cancer Journal for Clinicians, 65, 5-29. http://dx.doi.org/10.3322/caac.21254

[2] Shioyama, Y., Tokuuye, K., Okumura, T., Kagei, K., Sugahara, S., Ohara, K., et al. (2003) Clinical Evaluation of Proton Radiotherapy for Non-Small-Cell Lung Cancer. International Journal of Radiation Oncology ${ }^{*}$ Biology ${ }^{\star}$ Physics, 56, 7-13. http://dx.doi.org/10.1016/S0360-3016(02)04416-4

[3] Chang, J.Y., Zhang, X., Wang, X., Kang, Y., Riley, B., Bilton, S., et al. (2006) Significant Reduction of Normal Tissue Dose by Proton Radiotherapy Compared with Three-Dimensional Conformal or Intensity-Modulated Radiation Therapy in Stage I or Stage III NonSmall-Cell Lung Cancer. International Journal of Radiation Oncology ${ }^{\star}$ Biology ${ }^{\star}$ Physics, 65, 1087-1096. http://dx.doi.org/10.1016/j.ijrobp.2006.01.052

[4] Liu, W., Liao, Z., Schild, S.E., Liu, Z., Li, H., Li, Y., et al. (2015) Impact of Respiratory Motion on Worst-Case Scenario Optimized Intensity Modulated Proton Therapy for Lung 
Cancers. Practical Radiation Oncology, 5, e77-e86.

http://dx.doi.org/10.1016/j.prro.2014.08.002

[5] Vedam, S.S., Keall, P.J., Kini, V.R., Mostafavi, H., Shukla, H.P. and Mohan, R. (2002) Acquiring a Four-Dimensional Computed Tomography Dataset Using an External Respiratory Signal. Physics in Medicine and Biology, 48, 45-62.

http://dx.doi.org/10.1088/0031-9155/48/1/304

[6] Keall, P. (2004) 4-dimensional Computed Tomography Imaging and Treatment Planning. Seminars in Radiation Oncology, 14, 81-90. http://dx.doi.org/10.1053/j.semradonc.2003.10.006

[7] Pan, T., Lee, T.-Y., Rietzel, E. and Chen, G.T.Y. (2004) 4D-CT Imaging of a Volume Influenced By Respiratory Motion on Multi-Slice CT. Medical Physics, 31, 333-340.

http://dx.doi.org/10.1118/1.1639993

[8] Rietzel, E., Chen, G.T.Y., Choi, N.C. and Willet, C.G. (2005) Four-Dimensional ImageBased Treatment Planning: Target Volume Segmentation and Dose Calculation in the Presence of Respiratory Motion. International Journal of Radiation Oncology Biology Physics, 61, 1535-1550. http://dx.doi.org/10.1016/j.ijrobp.2004.11.037

[9] Rietzel, E., Pan, T. and Chen, G.T.Y. (2005) Four-Dimensional Computed Tomography: Image Formation and Clinical Protocol. Medical Physics, 32, 874-889. http://dx.doi.org/10.1118/1.1869852

[10] Castillo, S.J., Castillo, R., Balter, P., Pan, T., Ibbott, G., Hobbs, B., et al. (2014) Assessment of a Quantitative Metric for 4D CT Artifact Evaluation by Observer Consensus. Journal of Applied Clinical Medical Physics, 15, 4718.

[11] Yan, D., Jaffray, D.A. and Wong, J.W. (1999) A Model to Accumulate Fractionated Dose in a Deforming Organ. International Journal of Radiation Oncology ${ }^{\star}$ Biology ${ }^{\star}$ Physics, 44, 665-675. http://dx.doi.org/10.1016/S0360-3016(99)00007-3

[12] Brock, K.K., McShan, D.L., Haken, R.K.T., Hollister, S.J., Dawson, LA. and Balter, J.M. (2003) Inclusion of Organ Deformation in Dose Calculations. Medical Physics, 30, 290-295. http://dx.doi.org/10.1118/1.1539039

[13] Song, W., Schaly, B., Bauman, G., Battista, J. and Van Dyk, J. (2005) Image-Guided Adaptive Radiation Therapy (IGART): Radiobiological and Dose Escalation Considerations for Localized Carcinoma of the Prostate. Medical Physics, 32, 2193-2203.

http://dx.doi.org/10.1118/1.1935775

[14] Lu, W., Chen, M.-L., Olivera, G.H., Ruchala, K.J. and Mackie, T.R. (2004) Fast Free-Form Deformable Registration via Calculus of Variations. Physics in Medicine and Biology, 49, 3067-3087. http://dx.doi.org/10.1088/0031-9155/49/14/003

[15] Suryanto, A., Herlambang, K. and Rachmatullah, P. (2005) Comparison of Tumor Density by CT Scan Based on Histologic Type in Lung Cancer Patients. Acta Medica Indones, 37, 195-198.

[16] Seppenwoolde, Y., Shirato, H., Kitamura, K., Shimizu, S., van Herk, M., Lebesque, J.V., et al. (2002) Precise and Real-Time Measurement of 3D Tumor Motion in Lung Due to Breathing and Heartbeat, Measured During Radiotherapy. International Journal of Radiation Oncology Biology Physics, 53, 822-834. http://dx.doi.org/10.1016/S0360-3016(02)02803-1

[17] Mageras, G.S., Pevsner, A., Yorke, E.D., Rosenzweig, K.E., Ford, E.C., Hertanto, A., et al. (2004) Measurement of Lung Tumor Motion Using Respiration-Correlated CT. International Journal of Radiation Oncology, Biology, Physics, 60, 933-941.

http://dx.doi.org/10.1016/S0360-3016(04)01078-8 
[18] Shah, C., Grills, I.S., Kestin, L.L., McGrath, S., Ye, H., Martin, S.K., et al. (2012) Intrafraction Variation of Mean Tumor Position during Image-Guided Hypofractionated Stereotactic body Radiotherapy for Lung Cancer. International Journal of Radiation Oncology Biology Physics, 82, 1636-1641. http://dx.doi.org/10.1016/j.ijrobp.2011.02.011

[19] Wang, H., Dong, L., O’Daniel, J., Mohan, R., Garden, A.S., Ang, K.K., et al. (2005) Validation of an Accelerated "Demons" Algorithm for Deformable Image Registration in Radiation Therapy. Physics in Medicine and Biology, 50, 2887-2905.

http://dx.doi.org/10.1088/0031-9155/50/12/011

[20] Schaffner, B. and Pedroni, E. (1998) The Precision of Proton Range Calculations in Proton Radiotherapy Treatment Planning: Experimental Verification of the Relation between CT-HU and Proton Stopping Power. Physics in Medicine and Biology, 43, 1579-1592. http://dx.doi.org/10.1088/0031-9155/43/6/016

[21] Schneider, U., Pedroni, E. and Lomax, A. (1996) The Calibration of CT Hounsfield Units for Radiotherapy Treatment Planning. Physics in Medicine and Biology, 41, 111-124. http://dx.doi.org/10.1088/0031-9155/41/1/009

[22] Kang, Y., Zhang, X., Chang, J.Y., Wang, H., Wei, X., Liao, Z., et al. (2007) 4D Proton Treatment Planning Strategy for Mobile Lung Tumors. International Journal of Radiation Oncology Biology Physics, 67, 906-914. http://dx.doi.org/10.1016/j.ijrobp.2006.10.045

\section{Submit or recommend next manuscript to SCIRP and we will provide best service} for you:

Accepting pre-submission inquiries through Email, Facebook, LinkedIn, Twitter, etc.

A wide selection of journals (inclusive of 9 subjects, more than 200 journals)

Providing 24-hour high-quality service

User-friendly online submission system

Fair and swift peer-review system

Efficient typesetting and proofreading procedure

Display of the result of downloads and visits, as well as the number of cited articles

Maximum dissemination of your research work

Submit your manuscript at: http://papersubmission.scirp.org/

Or contact ijmpcero@scirp.org 